\title{
Avaliação da Sazonalidade Reprodutiva de Carneiros Santa Inês Criados no Distrito Federal
}

\author{
Rodrigo Duarte Martins ${ }^{1}$, Concepta McManus ${ }^{2}$, Alexandre Sardinha Carvalhêdo ${ }^{2}$, \\ Hudson Viana Borges ${ }^{1}$, Antônio Emídio Dias Feliciano Silva ${ }^{3}$, Natália Ribeiro dos Santos ${ }^{2}$
}

\begin{abstract}
RESUMO - Foram usados cinco machos, com idades entre um e cinco anos, com o objetivo de avaliar a sazonalidade reprodutiva de carneiros da raça Santa Inês nas condições climáticas do Distrito Federal. A cada 15 dias, aproximadamente, estes animais eram pesados e submetidos ao exame andrológico, durante o período de um ano. As características testiculares observadas incluíram perímetro escrotal (PE), comprimento (COMP), largura (LARG) e volume escrotal (VOL). A coleta de sêmen foi realizada utilizando eletroejaculador, sendo analisadas as seguintes características seminais: turbilhonamento (TURB), motilidade progressivo individual (MOT), vigor (VIG) e total de espermatozóides normais (TOTNOR). Data de coleta, reprodutor e peso corporal afetaram significativamente as características testiculares estudadas, no entanto, o PE não variou em função do peso corporal. Durante a estação seca, ocorreu redução significativa no tamanho dos testículos. Maiores PEs foram encontrados no período chuvoso. O TURB, a MOT e o VIG variaram em função do reprodutor, enquanto o TOTNOR variou em função da data de coleta. Na estação seca, as anormalidades espermáticas aumentaram significativamente, principalmente as de cabeça e peça intermediária. Somente o sêmen coletado na estação chuvosa pôde ser considerado satisfatório. Observou-se alta e positiva correlação entre o peso corporal e as características testiculares. Não foi observada correlação entre o PE e o TOTNOR. As variações estacionais na qualidade seminal podem levar a falsos diagnósticos de subfertilidade em carneiros. A correlação entre o peso corporal e as características testiculares, além do efeito da época do ano, enfatizam a importância de fazer a seleção de carneiros com base nas características testiculares durante a estação chuvosa.
\end{abstract}

Palavras-chave: carneiros, sazonalidade, sêmen, tamanho testicular

\section{Evaluation of the Reproductive Seasonality of Santa Inês Rams Raised in Distrito Federal}

\begin{abstract}
Five Santa Inês rams, between one and five years old, were selected evaluate the reproductive seasonality of the Santa Inês rams in the climatic conditions of Distrito Federal. Approximately every fortnight, for one year, these rams were weighed and underwent an andrological exam. The following testicular characteristics were evaluated: scrotal circumference (PE), testicular length (COMP), width (LARG) and volume (VOL). Semen collection was carried out with an eletroejaculator, and the following seminal characteristics were evaluated: mass motility (TURB), progressive motility (MOT), vigor (VIG) and total of normal spermatozoa (TOTNOR). Date of collection, ram and body weight affected testicular characteristics, but PE did not vary with the body weight. The highest PE was found in the rainy season. TURB, MOT and VIG varied in accordance with the ram, and TOTNOR varied in accordance with the date of collection. During the dry season, the spermatozoa abnormalities increased significantly, mainly head and midpiece abnormalities. Only the semen collected in the rainy season was considered acceptable. A high positive correlation between the body weight and the testicular characteristics was observed. No significant correlation was observed between PE and TOTNOR. The seasonal variation in the semen quality can cause false diagnostic of subfertility in rams. The correlation between body weight and testicular characteristics, as well as the effect of season, confirm that the selection of rams based on the testicular characteristics must be made in the rainy season.
\end{abstract}

Key Words: rams, seasonality, semen, testicular size

\section{Introdução}

A população de ovinos deslanados está em crescimento no Distrito Federal (DF), Mato Grosso e Mato Grosso do Sul e com tendência de estabilização em Goiás (IBGE, 1997). Nos Estados de Mato Grosso e Mato Grosso do Sul estão os maiores rebanhos do Centro Oeste, todavia, a maior concentração de animais está no Distrito Federal com 0,48 cabeças $/ \mathrm{km}^{2}$, seguido de Goiás, com 0,28 cabeças $/ \mathrm{km}^{2}$. Na região

\footnotetext{
${ }^{1}$ Aluno de Medicina Veterinária, PIBIC, FAV, UnB, 70910-970, Brasília - DF.

2 Professor, Faculdade de Agronomia e Medicina Veterinária (FAV), Universidade de Brasília (UnB), CEP: 70910-970, Brasília - DF. E.mail: concepta@unb.br

3 Pesquisador, EMBRAPA - Cenargen, SAIN Parque Rural, Final Av. W5 Norte, 70770-900, Brasília-DF. E.mail: emidio@cenargen.embrapa.br
} 
Centro Oeste, tem-se notado forte interesse dos produtores em aumentar os seus rebanhos, assim como a introdução de novos criadores para o setor.

Hoje, a demanda pela carne ovina no Distrito Federal é maior que a oferta local, obrigando a importação de outros estados. Por isso, a Secretaria de Agricultura do DF (SADF, 1999), com o objetivo de fortalecer o setor rural, lançou o PróRural, que enfatiza a substituição de produtos de outros estados e países que podem ser produzidos na própria região. Este programa visa que a ovinocultura local venha abastecer $30,0 \%$ do mercado em crescimento com a produção local de carne de ovino, através do desenvolvimento de diversos programas relacionados com a melhoria genética e aumento do rebanho local de ovinos, com a aquisição de animais e execução de campanhas de acompanhamento do desempenho dos animais.

O melhoramento visando a eficiência da produção de carne ovina fundamenta-se em seleção e sistemas de acasalamento de animais superiores, produzindo câmbios genéticos pequenos, porém cumulativos, na produção de sucessivas progênies. Qualquer resposta à seleção deve passar, impreterivelmente, pela caracterização do potencial reprodutivo nas condições do Brasil Central, importante etapa na exploração de ovinos.

No DF, até agora, os trabalhos com ovinos haviam se preocupado em examinar características morfológicas, fisiológicas e sanitárias de algumas raças, como a Bergamácia, a Santa Inês e a Morada Nova, além de estudar os fatores que influenciam a produção e a reprodução destas raças (McManus \& Miranda, 1997; Miranda \& McManus, 2000; Quesada, 2000), desconsiderando, contudo, em sua maioria, o macho. Como salientaram Feliciano Silva \& Nunes (1984), na preocupação de incrementar os índices reprodutivos do rebanho ovino, muitas vezes são intensificados os estudos da fêmea sendo ignorado os fatores ligados ao macho.

$\mathrm{Na}$ atualidade, ainda se sabe muito pouco a respeito do desempenho reprodutivo de carneiros explorados no Planalto Central. Portanto, o objetivo deste trabalho foi realizar a avaliação da sazonalidade reprodutiva de carneiros da raça Santa Inês nas condições climáticas do Distrito Federal.

\section{Material e Métodos}

O estudo foi realizado em um dos mais antigos e maiores criatórios de ovinos em Brasília. É uma exploração industrial, onde os machos são criados para abate e/ou venda como reprodutores e as fêmeas irão se constituir nas futuras matrizes do rebanho. A propriedade localiza-se a $15^{\circ} 47^{\prime}$ de latitude sul e $47^{\circ} 56^{\prime}$ de longitude oeste, na rodovia DF-100, Colônia Agrícola Itapeti, Distrito Federal. A temperatura ambiente média anual da região é de $21,1^{\circ} \mathrm{C}$, tendo $-1,6$ e $34^{\circ} \mathrm{C}$ como mínima e máxima absoluta, respectivamente. A precipitação anual média é de $1.578,5 \mathrm{~mm}$ e a média anual de umidade relativa do ar, de $68,0 \%$. O clima caracteriza-se por duas estações bem definidas, uma das águas, de outubro a abril, em que ocorre quase toda a precipitação, e outra seca, de maio a setembro, quase sem chuvas. A precipitação média mensal, durante o período chuvoso, foi de $177,44 \mathrm{~mm}^{3}$ e durante o período seco, de $19,7 \mathrm{~mm}^{3}$.

Foram selecionados cinco machos da raça Santa Inês, com idade entre um e cinco anos. Em geral, a cada 15 dias, estes animais foram pesados e submetidos ao exame andrológico, durante o período de um ano. Os animais foram mantidos em regime semiextensivo de manejo, com aproximadamente 20 hectares de pastagem de Andropogon gayanus, sendo suplementados, no período da seca, com cana desintegrada, milho em grão e silagem de milho. $\mathrm{O}$ sal mineral foi fornecido à vontade.

Foram observadas as seguintes características testiculares: perímetro escrotal (PE), comprimento (COMP), largura (LARG) e volume escrotal (VOL). $\mathrm{O} P E$ foi medido por meio de fita métrica na região mediana dos testículos e o COMP e a LARG foram mensurados usando o paquímetro. Para medir o COMP, foram considerados os testículos, excluindo a cauda dos epidídimos no sentido dorso-ventral. Para calcular o VOL foi utilizada a fórmula que mais se aproxima do valor obtido pelo deslocamento de líquido (Fields et al.,1979): $\mathrm{VOL}=2 \mathrm{x}\left[(\mathrm{LARG} / 2)^{2} \mathrm{x}\right.$ $\mathrm{P} \times(\mathrm{COMP})]$.

A coleta de sêmen foi realizada utilizando eletroejaculador e as seguintes características seminais foram analisadas: turbilhonamento (TURB), motilidade individual progressiva (MOT), vigor (VIG) e total de espermatozóides normais (TOTNOR), de acordo com as recomendações do Colégio Brasileiro 
de Reprodução Animal (CBRA, 1998).

O modelo utilizado na análise dos dados considerou a data de coleta como fator fixo e o animal como fator aleatório. O modelo usado foi o seguinte:

$$
\mathrm{Y}_{\mathrm{ijk}}=\mathrm{d}_{\mathrm{i}}+\mathrm{a}_{\mathrm{j}}+\text { peso }_{\mathrm{ij}}+\mathrm{e}_{\mathrm{ijk}}
$$

em que: $Y_{i j k}=$ característica analisada; $d_{i}=$ fator fixo da data de coleta dos dados; $\mathrm{a}_{\mathrm{j}}=$ fator aleatório relativo ao animal estudado; peso $_{\mathrm{ij}}=$ covariável do peso do animal na hora da coleta; $\mathrm{e}_{\mathrm{ijk}}=$ erro aleatório.

Os dados foram analisados por intermédio do programa estatístico SAS (1999) utilizando os procedimentos GLM (modelo linear geral) e CORR (correlações), usando o modelo medidas repetidas.

\section{Resultados e Discussão}

Os testículos dos animais estudados apresentaram-se simétrico, dessa forma, utilizou-se para o cálculo do VOL as medidas do testículo direito. O resumo da análise de variância está apresentado na Tabela 1. Data de coleta, reprodutor e peso corporal afetaram as características testiculares estudadas.

Ao contrário do que foi observado por Vilar-Filho et al. (1993) e Moraes \& Oliveira (1996), o PE não variou em função do peso corporal. No presente trabalho, a data de coleta e o reprodutor foram considerados as fontes de variação mais importantes. A inclusão do macho como fator aleatório no modelo e/ou devido à baixa variação do peso dos mesmos pode ter reduzido a variação do $\mathrm{PE}$, em função do peso.

O PE variou entre 29 e $33 \mathrm{~cm}$, ficando um pouco abaixo do que foi observado por Salgueiro \& Nunes
(1999), que encontraram valores para o PE entre 30 e $36 \mathrm{~cm}$ entre reprodutores Santa Inês. Contudo, deve ser considerado que no referido trabalho os reprodutores eram animais provenientes de rebanhos de elite, destinados à exposição, ou seja, em sua maioria de elevado padrão genético, bem nutridos, tendo sido realizada apenas uma medição, desconsiderando a época do ano, fator que age como importante fonte de variação nesta característica.

A variação das características testiculares entre os reprodutores observada na Tabela 1, pode indicar diferenças genéticas entre os animais (Moares \& Oliveira, 1996), porém, neste caso as variações parecem refletir o fato dos animais pertencerem a grupos contemporâneos diferentes. Moraes \& Oliveira (1991) enfatizaram que qualquer esforço de seleção quanto a tamanho testicular (PE e VOL) deve ser efetuado em grupos contemporâneos.

A influência da época do ano é observada na Figura 1, revelando que, durante a estação seca, ocorre redução significativa no tamanho dos testículos. Maior PE encontrado no período chuvoso também foi observado por Simplicio et al. (1982) e Freitas \& Nunes (1992).

Garcia-Deragon et al. (1985) e Martin et al. (1994) relacionaram maior PE no período chuvoso com a melhor condição nutricional, pois, no decorrer deste período, observou-se maior aporte de qualidade e quantidade de volumoso. Segundo Martin et al. (1994), os efeitos das mudanças na dieta sobre o tamanho do testículo de carneiros são causados parcialmente por mudanças na atividade do sistema

Tabela 1 - Resumo da análise de variância para características testiculares de carneiros Santa Inês explorados no Distrito Federal

Table 1 - Summary of analysis of variance for testicular characteristics of Santa Inês rams raised in the Federal District

\begin{tabular}{|c|c|c|c|c|c|}
\hline \multirow[t]{2}{*}{$\begin{array}{l}\text { Característica } \\
\text { Characteristics }\end{array}$} & \multirow[t]{2}{*}{$\begin{array}{l}\mathrm{N} \\
N\end{array}$} & \multirow{2}{*}{$\begin{array}{c}\text { Média } \\
\text { Desvio-padrão } \\
\text { Standard deviation }\end{array}$} & \multicolumn{3}{|c|}{$\begin{array}{l}\text { Fonte de variação } \\
\text { Source of variation }\end{array}$} \\
\hline & & & $\begin{array}{c}\text { Data da coleta } \\
\text { Date of collection }\end{array}$ & $\begin{array}{l}\text { Reprodutor } \\
\text { Ram }\end{array}$ & $\begin{array}{l}\text { Peso corporal } \\
\text { Body weight }\end{array}$ \\
\hline $\begin{array}{l}\mathrm{PE}(\mathrm{cm}) \\
P E(\mathrm{~cm})\end{array}$ & 90 & $31,4(1,9)$ & $* *$ & $* *$ & NS \\
\hline $\begin{array}{l}\text { COMPTD }(\mathrm{cm}) \\
\text { COMPTD }(\mathrm{cm})\end{array}$ & 90 & $9,54(0,95)$ & $* *$ & $* *$ & $* *$ \\
\hline $\begin{array}{l}\operatorname{LARGTD}(\mathrm{cm}) \\
L A R G T D(\mathrm{~cm})\end{array}$ & 90 & $6,59(0,61)$ & $* *$ & $* *$ & $*$ \\
\hline $\begin{array}{l}\text { VOL }\left(\mathrm{cm}^{3}\right) \\
\operatorname{VOL}\left(\mathrm{cm}^{3}\right)\end{array}$ & 90 & $667,6(188,04)$ & $* *$ & $* *$ & $* *$ \\
\hline
\end{tabular}

$\mathrm{PE}=$ perímetro escrotal; $\mathrm{COMPTD}=$ comprimento testicular direito; $\mathrm{LARGTD}=$ largura testicular direita; $\mathrm{VOL}=$ volume escrotal; ${ }^{\mathrm{P}}<0,05$; ${ }^{* *} \mathrm{P}<0,01$; NS: não significativo.

$P E=$ scrotal circumference; COMPTD = right testicular length; $L A R G T D=$ right testicular width; VOL = scrotal volume; * $P<.05 ;{ }^{* *} P<.01 ; N S:$ not significant. 
hipotalâmico controlador da secreção de gonadotrofinas. Aparentemente, existe um mecanismo independente do GnRH envolvido no efeito da dieta sobre o crescimento testicular. Assim, de acordo com a informação desses autores, a falta de relação entre dieta, massa testicular e produção de hormônios testiculares sugere que a nutrição afeta mais prontamente os compartimentos somáticos e gametogênicos do testículo do que os compartimentos endócrinos.

O VOL apresentou comportamento semelhante ao CMPTD e à LARGTD (Figura 1). A medição do VOL surgiu da preocupação em aumentar a precisão na escolha de reprodutores. Tem sido sugerido que o volume testicular é a medida mais apurada do potencial reprodutivo dos machos bovinos (Unanian et al., 2000). O VOL representa melhor a quantidade de parênquima testicular, sendo particularmente a medida mais apurada que o PE, quando se tem animais com testículo longo e fino. O PE, neste caso, subestimaria o potencial reprodutivo destes animais (Bailey et al., 1996).

A análise da variância das características seminais é apresentada na Tabela 2. O TURB, a MOT e o VIG variaram somente em função do reprodutor, enquanto o TOTANOR e o TOTNOR variaram em função da data de coleta.

Diferenças significativas $(\mathrm{P}<0,01)$ nas características seminais entre os reprodutores (Tabela 2) da mesma raça também foram observadas por Simplício et al. (1982) e Karagiannidis et al. (2000). Essas
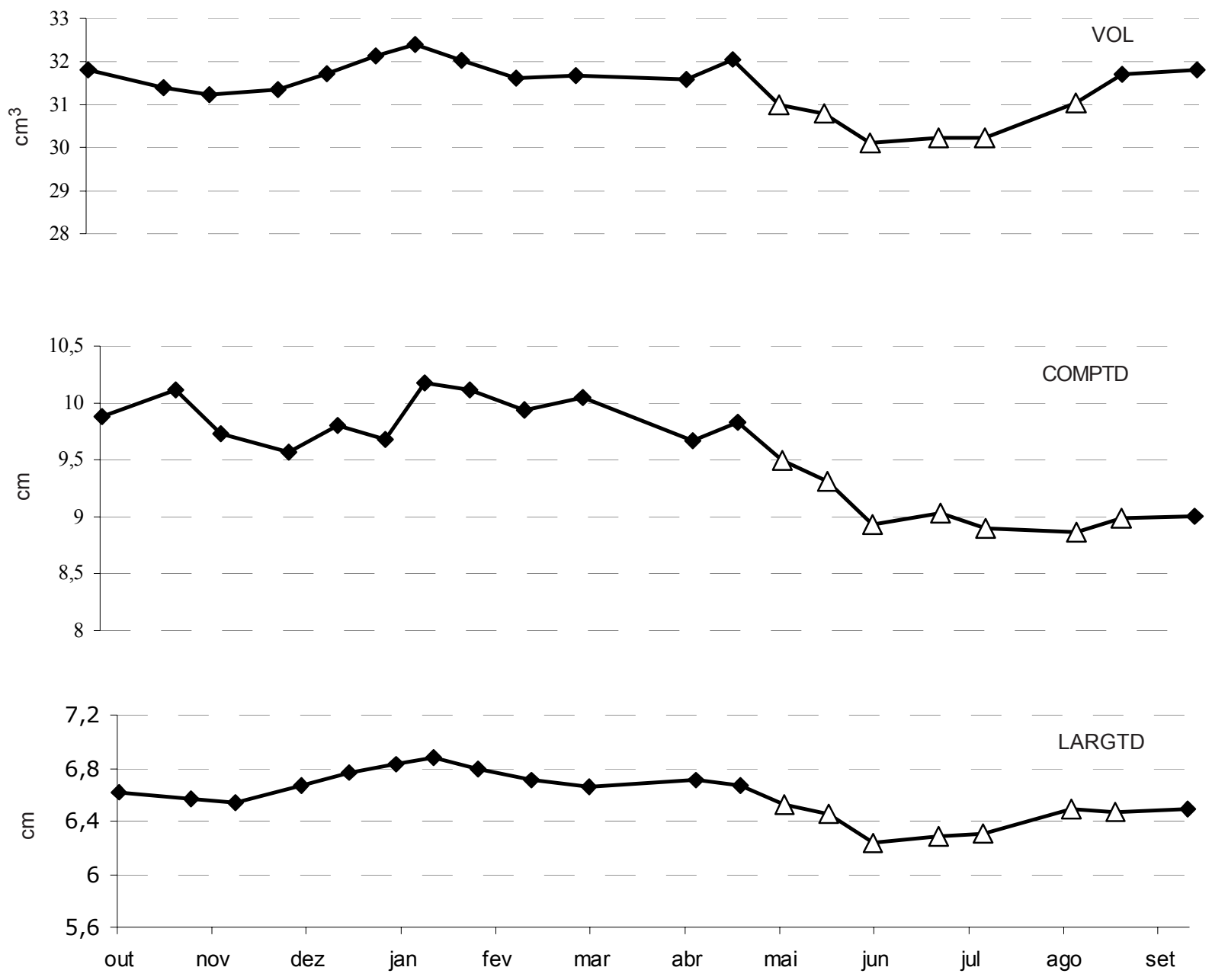

* Marcadores com formato diferente indicam diferenças significativas $(P<0,05)$.

* Markers with different shape indicate significant $(P<.05)$ differences.

Figura 1 - Efeito do mês sobre o tamanho testicular em ovinos Santa Inês no Distrito Federal.

Figure 1 - Effect of month on testicular size in Santa Inês rams in the Federal District. 
Tabela 2 - Resumo da análise de variância para características seminais de carneiros Santa Inês explorados no Distrito Federal

Table 2 - Summary of analysis of variance for seminal characteristics of Santa Inês rams raised in Federal District

\begin{tabular}{|c|c|c|c|c|c|}
\hline \multirow[t]{2}{*}{$\begin{array}{l}\text { Característica } \\
\text { Characteristics }\end{array}$} & \multirow[t]{2}{*}{$\begin{array}{l}\mathrm{N} \\
N\end{array}$} & \multirow{2}{*}{$\begin{array}{c}\text { Média } \\
\text { Desvio-padrão } \\
\text { Standard deviation }\end{array}$} & \multicolumn{3}{|c|}{$\begin{array}{l}\text { Fonte de variação } \\
\text { Source of variation }\end{array}$} \\
\hline & & & $\begin{array}{c}\text { Data da coleta } \\
\text { Date of collection }\end{array}$ & $\begin{array}{l}\text { Reprodutor } \\
\text { Ram }\end{array}$ & $\begin{array}{c}\text { Peso corporal } \\
\text { Bodyweight }\end{array}$ \\
\hline $\begin{array}{l}\text { TURB }(0-5) \\
\text { TURB }(0-5)\end{array}$ & 88 & $1,98(0,37)$ & $\mathrm{NS}$ & $* *$ & NS \\
\hline $\begin{array}{l}\text { MOT }(\%) \\
\text { MOT (\%) }\end{array}$ & 88 & $63,92(12,85)$ & NS & $*$ & NS \\
\hline $\begin{array}{l}\operatorname{VIG}(0-5) \\
\operatorname{VIG}(0-5)\end{array}$ & 88 & $1,99(0,27)$ & NS & $* *$ & NS \\
\hline $\begin{array}{l}\text { TOTANOR }(\%) \\
\text { TOTANOR (\%) }\end{array}$ & 88 & $21,14(7,79)$ & $* *$ & NS & NS \\
\hline $\begin{array}{l}\text { TOTNOR }(\%) \\
\text { TOTNOR }(\%)\end{array}$ & 88 & $78,85(7,79)$ & $* *$ & NS & NS \\
\hline
\end{tabular}

TURB = turbilhonamento; MOT = motilidade; VIG = vigor; TOTANOR = total de espermatozóides anormais; TOTNOR = total de espermatozóides normais; * $\mathrm{P}<0,05 ;{ }^{* *} \mathrm{P}<0,01$; NS: não significativo.

TURB = mass motility; $M O T=$ motility; VIG = vigor; TOTANOR = total of abnormal spermatozoa; $T O T N O R=$ total of normal spermatozoa; * $P<0.05 ; * * P<0.01$; NS: not significant.

diferenças são atribuídas principalmente à variação genética individual de cada reprodutor, já que a idade parece não afetar a espermatogênese nos carneiros após a puberdade (Selaive-Vilarroel \& Moraes, 1987).

Karagiannidis et al. (2000), trabalhando em região de clima temperado, observaram que a época do ano influencia na MOT, encontrando valores piores no verão. A variação verificada pelos autores foi atribuída ao fotoperiodismo.

Trabalhando no Nordeste brasileiro e coletando o sêmen dos animais através de vagina artificial, Freitas \& Nunes (1992) observaram a influência da época do ano sobre a MOT, encontrando melhores resultados na época chuvosa. No presente trabalho, não se observou variação da MOT devido à época do ano $(\mathrm{P}>0,05)$. O uso da eletroejaculação não deve ter prejudicado a avaliação da característica, já que Mandiki et al. (1998), Rege et al. (2000) e Feliciano Silva \& Nunes (1984), apesar de terem trabalhado com a vagina artificial, em regiões de clima tropical, também não observaram variação da MOT ao longo das estações do ano.

Com relação ao TOTNOR, Karagiannidis et al. (2000) também observaram variação tanto entre reprodutores quanto entre estações do ano. Já Feliciano Silva \& Nunes (1984) não observaram variação deste parâmetro entre reprodutores, entre raças, Santa Inês e Somalis Brasileira e, entre épocas do ano. Selaive-Villarroel et al. (1985a) verificaram influência significativa tanto da raça quanto da época do ano sobre a porcentagem de espermatozóides anormais ao trabalharem com machos Merino, Ideal e Corriedale.

Segundo o CBRA (1998) os padrões seminais desejáveis para seleção de carneiros para a monta natural são: $\mathrm{MOT}=70 \%, \mathrm{VIG}=3, \mathrm{TURB}=3 \mathrm{e}$ TOTANOR $=20,0 \%$. A média geral encontrada no presente trabalho se encontra abaixo destas recomendações, no entanto, deve-se levar em conta que a seleção dos animais experimentais foi feita com base, apenas no seu ganho de peso, desconsiderando outros fatores que deveriam fazer parte do processo de seleção. Ainda deve ser considerado o fato destes reprodutores estarem em serviço durante todo o período experimental, fato que pode contribuir para menor qualidade seminal (Selaive-Vilarroel \& Moraes, 1987).

Moraes (1997), em extensa revisão a respeito da avaliação reprodutiva do carneiro, recomenda que devem ser considerados aptos para a cobertura aqueles animais sem alterações clínicas, apresentando MOT $>50,0 \%$, VIG $>2$ e TOTNOR $>60,0 \%$. A média geral encontrada no presente trabalho está de acordo com está recomendação.

Observa-se na Figura 2 o efeito da época do ano sobre o TOTANOR, constatando-se que, na estação seca, as anormalidades espermáticas aumentaram significativamente $(\mathrm{P}<0,05)$.

Resultados semelhantes também foram observados por Rege et al. (2000), que encontraram sêmen com maior porcentagem de anormalidades na época 


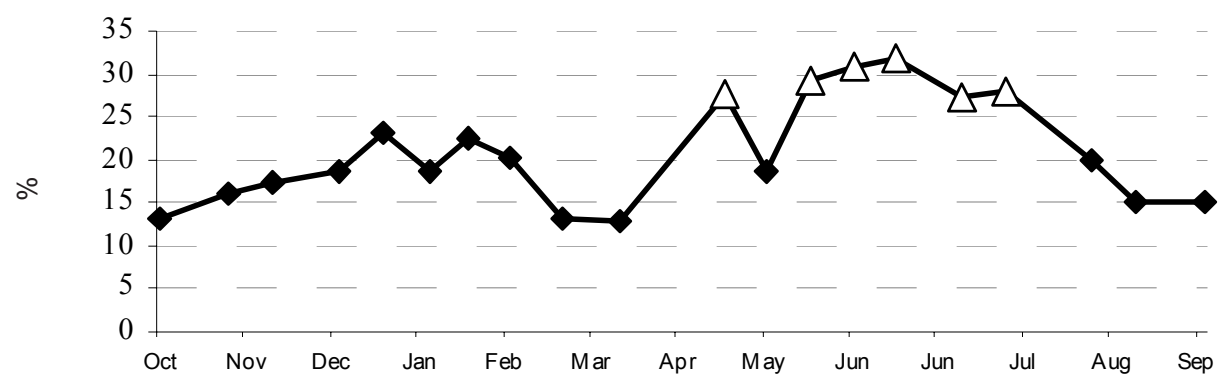

Figura 2 - Quadrados médios mínimos para a percentagem de espermatozóides anormais (TOTANOR) em função da época do ano em carneiros Santa Ines criados no Distrito Federal.

Figure 2 - Least mean squares for the percentage of abnormal spermatozoa (TOTANOR) along the year in Santa Inês rams in the Federal District.

* Marcadores com formato diferente indicam diferenças significativas $(P<0,05)$.

* Markers with different shape indicate significant differences $(P<.05)$.

seca, na África tropical. Simplicio et al. (1982) também encontraram sêmen de melhor qualidade durante a época chuvosa e no período de transição chuvaseca. Feliciano Silva \& Nunes (1984) e Freitas \& Nunes (1992) não observaram diferenças entre as estações seca e chuvosa em termos de anormalidade espermática. No entanto, os valores sempre tenderam a ser mais elevados para patologias na estação seca, porém dentro dos níveis permitidos para se atingir uma boa fertilidade.

Em regiões temperadas, a sazonalidade dos carneiros no tocante a qualidade do sêmen é atribuída a combinação entre fotoperíodo e temperatura, enquanto em regiões tropicais o efeito ambiental parece estar mais relacionado com a chuva e seu efeito na quantidade e qualidade da forragem (Rege et al., 2000).

Simplício et al. (1982) atribuíram o fato de ter encontrado sêmen de melhor qualidade na estação chuvosa à maior disponibilidade de forragem verde que resultou em melhora geral das condições dos carneiros. Selaive-Villarroel et al. (1985a) também indicaram, como a causa da maior taxa de anormalidade espermática, as condições deficientes das pastagens naturais. Freitas \& Nunes (1992) descrevem que, na seca, há deficiência de substratos para produção de energia, o que prejudica a espermatogênese.

É importante considerar que a espermatogênese nos pequenos ruminantes domésticos tem duração aproximada de 49 dias, o que suporta a recomendação de oferecer suplementação alimentar ao reprodutor a partir de oito a seis semanas antes do início da estação de monta (Simplicio et al., 1990). A melhora significativa na qualidade do sêmen traduzida pelo aumento no número de espermatozóides normais, no volume e na concentração espermática, aliados à oportunidade de melhorar o controle sanitário, faz com que a suplementação alimentar dos carneiros, antes do acasalamento, seja uma norma de manejo recomendável (Selaive-Villarroel et al., 1985b).

No presente estudo, os animais foram suplementados durante a estação seca, entretanto, na estação chuvosa a quantidade e a qualidade da forragem foram superiores as encontradas na seca, sendo portanto, muito pouco provável que a suplementação tenha conseguido compensar esta diferença. A precipitação durante a época chuvosa foi superior a da época seca. Esta variação na quantidade de chuva afetou diretamente as pastagens.

$\mathrm{Na}$ falta de suplementação adequada, pode ser mais interessante efetuar a estação de monta na estação chuvosa, porém isto pode propiciar taxas produtivas isto é peso ao nascer e peso à desmama menores, em função da prenhez transcorrer e ir a termo durante a época de carência alimentar (Machado et al, 1999). No entanto, mesmo quando os nascimentos ocorrem na época chuvosa, podem ocorrer quedas nas taxas reprodutivas devido a mortalidade das crias por pneumonias e por proliferação de eventuais patógenos no ambiente com maior umidade (Machado \& Simplício, 1998).

As fêmeas paridas na estação seca apresentam maior prolificidade possivelmente em decorrência de 
sua maior taxa de ovulação durante o acasalamento na época chuvosa (Feliciano Silva et al., 1987). Fato semelhante, em termos de capacidade fertilizante do sêmen, parece acontecer com os carneiros.

A MOT e o TOTNOR são considerados indicadores da função testicular (Moraes \& Oliveira, 1996). Segundo Colas (1981) e Rege et al. (2000), o total de espermatozóides normais é o melhor indicador do efeito da época do ano, pois este fator é muito correlacionado com o teste de fertilidade.

$\mathrm{Na}$ Tabela 3, observa-se que na época seca há aumento das anormalidades de cabeça e de peça intermediária, como foi observado por Rege et al. (2000). As anormalidades de cabeça e de peça intermediária também foram as anomalias mais comuns encontradas por Mickelsen et al.,(1982).

Devido ao efeito da época do ano sobre a taxa de normalidade espermática, somente o sêmen coletado na estação chuvosa pode ser considerado satisfatório,

Tabela 3 - Médias (+/- desvios-padrão) das patologias espermáticas encontradas nas estações chuvosa e seca em carneiros Santa Inês criados no Distrito Federal

Table 3 - Means (+/-standard deviations) for the spermatozoa pathology found in the rainy and dry seasons for Santa Inês rams raised in the Federal District

\begin{tabular}{lcc}
\hline $\begin{array}{l}\text { Patologias } \\
\text { Pathologies }\end{array}$ & $\begin{array}{c}\text { Época } \\
\text { chuvosa } \\
\text { Rainy } \\
\text { season }\end{array}$ & $\begin{array}{c}\text { Época } \\
\text { seca } \\
\text { Dry } \\
\text { season }\end{array}$ \\
\hline $\begin{array}{l}\text { TOTCAB }(\%) \\
\text { TOTCAB }(\%)\end{array}$ & $7,4(5,6)$ & $8,89(6,6)$ \\
TOTPI $(\%)$ & $8,46(6,1)$ & $13,39(6,9)$ \\
TOTPI $(\%)$ & $1,28(1,7)$ & $1,68(3,4)$ \\
TOTPP $(\%)$ & $1,2(1,5)$ & $0,86(1,6)$ \\
TOTPP $(\%)$ & $10,94(6,7)$ & $15,94(6,3)$ \\
TOTOUT $(\%)$ & $18,34(7,5)$ & $24,84(6,6)$ \\
TOTOUT $(\%)$ & & \\
TOTCAU $(\%)$ & & \\
TOTCAU $(\%)$ & & \\
TOTANOR $(\%)$ & TOTANOR $(\%)$ &
\end{tabular}

TOTCAB $=$ total de anormalidades de cabeça; TOTPP $=$ total de anormalidades de peça principal; TOTPI = total de anormalidades de peça intermediária; TOTOUT = total de outras anormalidades de cauda; TOTCAU = total de anormalidades de cauda (corresponde a soma de TOTPP, TOTPI e TOTOUT); TOTANOR= total de espermatozóides anormais (corresponde à soma de TOTCAB e TOTCAU).

TOTCAB = total of head abnormalities; TOTPP = total of mainpiece abnormalities; TOTPI = total of midpiece abnormalities; TOTOUT = total of other tail abnormalities; TOTCAU = total of tail abnormalities (corresponding to the sum of TOTPP, TOTPI and TOTOUT); TOTANOR = total of abnormal spermatozoa (corresponding to the sum of TOTCAB and TOTCAU). de acordo com as recomendações do CBRA (1998).

$\mathrm{Na}$ análise da Tabela 4, observa-se correlação alta e positiva $(0,82$ a 0,88$)$ entre o peso e as características testiculares, indicando maior desenvolvimento testicular dos animais mais pesados em relação aos mais leves. Lôbo et al. (1997) também observaram alta correlação entre o PE e o peso corporal em diferentes idades, indicando que a maior parte dos genes atuantes no desenvolvimento do PE, age no desenvolvimento do peso corporal.

Existem correlações altas e positiva $(0,86$ a $0,97)$ entre as características testiculares. Dessa forma, a mensuração do VOL testicular é uma medida que pode ser utilizada como indicadora do tamanho testicular.

Com relação às características seminais, foi observado correlação alta e positiva $(0,54$ a 0,79$)$ entre o TURB, o VIG e a MOT. O VIG se mostrou particularmente correlacionado com o TOTCAB $(-0,23)$ e o TOTPP $(-0,29)$, fato também observado por Mickelsen et al. (1982), Ibrahim (1997) e Rege et al. (2000).

O TOTCAB e o TOTPI mostraram-se correlacionados altamente e positivamente $(0,51 \mathrm{e}$ $0,62)$ nessa ordem, com o TOTANOR. Esta correlação indica que as anormalidades de cabeça e de peça intermediária foram as principais anormalidades encontradas nestes carneiros.

Não foi observada correlação entre o PE e o TOTNOR (Tabela 4), fato também descrito por Moraes \& Oliveira (1996). Estes autores afirmaram que, provavelmente, a associação entre $\mathrm{PE}$ e TOTNOR não é consistente, por ser indireta. Moraes (1997) salienta que carneiros com testículos pequenos podem apresentar sêmen de boa qualidade; portanto, a seleção de carneiros potencialmente mais férteis deve basear-se em todos os parâmetros empregados para estimar a eficiência reprodutiva e não apenas descartar os animais que não apresentaram associação entre peso corporal e tamanho testicular. O efeito do peso corporal sobre o PE muitas vezes pode ser sobrepujado por outras variáveis, como foi observado neste traba1ho. Neste contexto, Moraes \& Oliveira (1991) sugerem que a eleição dos reprodutores com maior PE dentro dos grupos contemporâneos funciona como critério complementar para a seleção efetuada com base nos parâmetros produtivos. Uma segunda etapa na escolha dos reprodutores deve 


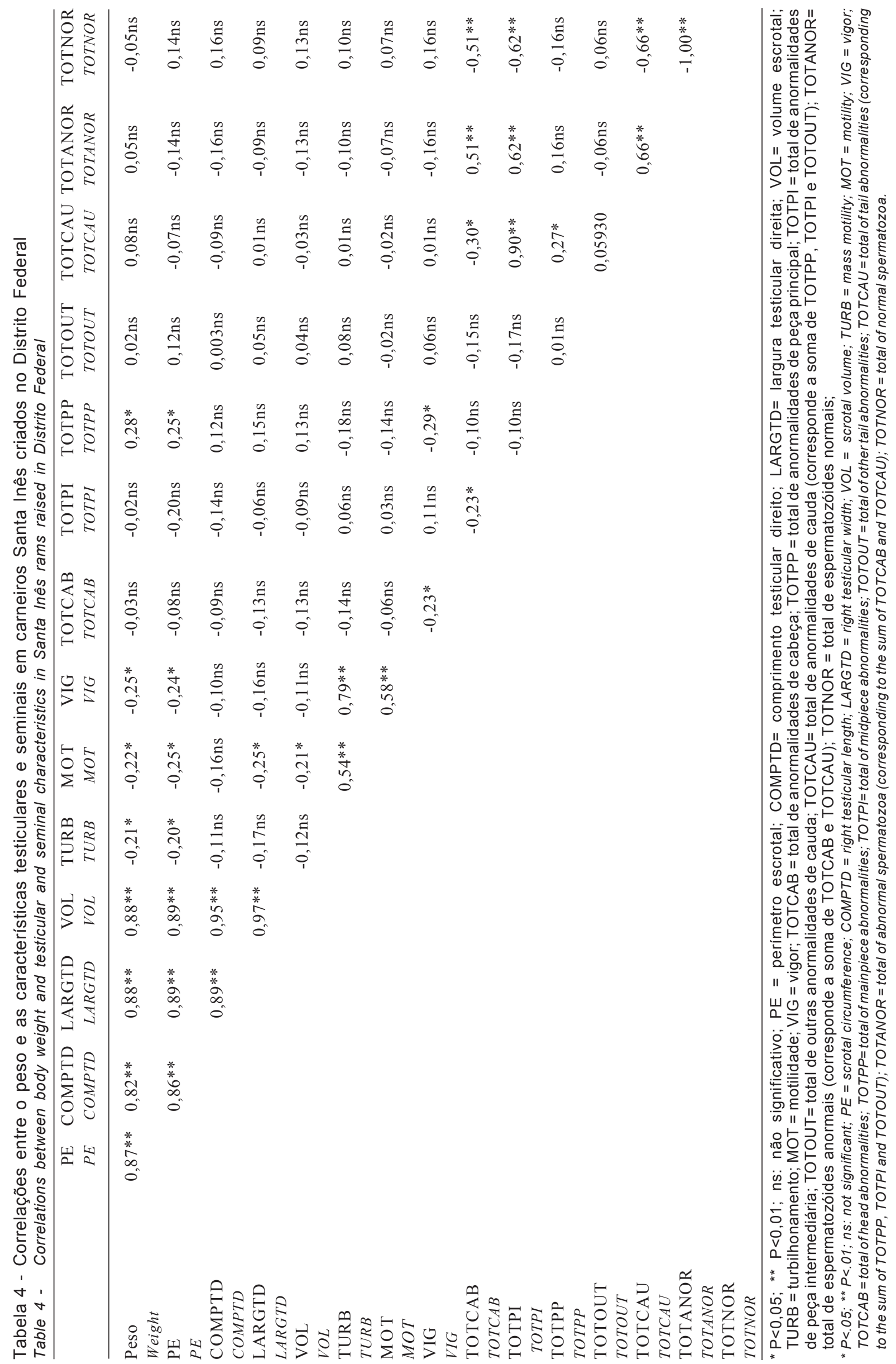


ser então efetuada previamente ao emprego destes animais na reprodução. Devem ser realizadas avaliações no sêmen e no comportamento de monta, além de testes sorológicos e microbiológicos visando a identificação de doenças tais como Brucelose Campilobacteriose, Trichomonose, entre outras associadas com a fertilidade.

A seleção complementar pelo PE estaria enfocando também aspectos relacionados à fertilidade, principalmente correlacionada com a maior taxa de ovulação nas filhas destes animais selecionados para maior PE (Moraes \& Oliveira, 1991). Entretanto, o uso potencial do tamanho testicular no processo de seleção de reprodutores ainda precisa ser mais bem estudado. Matos et al. (1992) e Moraes \& Oliveira (1996) salientaram que não existe muita confiabilidade nas correlações genéticas estimadas entre o PE e a taxa de fertilidade das ovelhas.

\section{Conclusões}

A associação entre o peso corporal e as características testiculares enfatiza a importância de que qualquer seleção de carneiros com base nas características testiculares deve ser feita quando eles estão com boa condição corporal (estação chuvosa). No entanto, devido à não observação de uma relação consistente entre as características testiculares e os indicadores da função testicular, a seleção de reprodutores com base nas características testiculares deve ser feita objetivando incorporar vantagens em outras características produtivas por correlações genéticas significativas com o tamanho testicular. Ainda são necessários mais estudos para se identificar a verdadeira relação das características testiculares com a fertilidade.

A qualidade seminal e, conseqüentemente, o diagnóstico de fertilidade foram afetados pelas variações estacionais, em carneiro da raça Santa Inês na região do Distrito Federal.

Os programas de melhoramento da raça Santa Inês devem levar em consideração as variações individuais e estacionais das características testiculares e seminais na região do Distrito Federal.

\section{Literatura Citada}

BAILEY, T.L.; MONKE, D.; HUDSON, R.S. et al. Testicular shape and its relationship to sperm production in mature Holstein bulls. Theriogenology, v.46, n.3, p.881-887, 1996. COLAS, G. Seasonal variations of semen quality in adult Ile-de-
France rams. I. Study of cell morphology and massal motility of sperm. Reproduction, Nutrition and Development, v.20, n.6, p.1789-1799, 1980.

COLÉGIO BRASILEIRO DE REPRODUÇÃO ANIMAL CBRA. Manual para exame e avaliação de sêmen animal. 2.ed. Belo Horizonte: 1998. 49p.

FELICIANO SILVA, A.E.D.; FOOTE, W.C.; RIERA, G.S. et al. Efeito do manejo nutricional sobre a taxa de ovulação e de folículos no decorrer do ano, em ovinos deslanados no Nordeste do Brasil. Pesquisa Agropecuária Brasileira, v.22, n.6, p.635-645, 1987.

FELICIANO SILVA, A.E.D.; NUNES, J.F. Estacionalidade na atividade sexual e qualidade do sêmen nos ovinos deslanados das raças Santa Inês e Somalis. Revista Brasileira de Reprodução Animal, v.8, n.4, p.207-214, 1984.

FILEDS, M.J.; BURNS, W.C.; WARNIC, A.C. et al. Age, season and breed effects on testicular volume and semen traits in young beef bulls. Journal of Animal Science, v.48, n.6, p.1299-1304, 1979.

FREITAS, V.J.F.; NUNES, J.F. Parâmetros andrológicos e seminais de carneiros deslanados criados na região litorânea do Nordeste Brasileiro em estação seca e chuvosa. Revista Brasileira de Reprodução Animal, v.16, n.3-4, p.95-104, 1992.

GARCIA-DERAGON, L.A.; PIMENTEL, C.A.; MORAES, J.C.F. et al. Variação estacional de características reprodutivas em carneiros com e sem lã no escroto. Revista Brasileira de Reprodução Animal, v.9, n.3, p.119-132, 1985.

IBRAHIM, S.A. Seasonal variations in semen quality of local and crossbred rams raised in the United Arab Emirates. Animal Reproduction Science, v.49, p.61-167, 1997.

INSTITUTO BRASILEIRO DE GEOGRAFIA E ESTATÍSTICA - IBGE. Censo Agropecuário. Rio de Janeiro, 1997. 381p.

KARAGIANNIDIS, A.; VARSAKELI, S.; ALEXOPOULOS, C. et al. Seasonal variation in semen characteristics of Chios and Friesian rams in Greece. Small Ruminant Research, v.37, p.125-130, 2000.

LÔBO, R.N.B.; MARTINS FILHO, R.; FERNANDES, A.A.O. Correlações entre o desenvolvimento do perímetro escrotal e caracteres de crescimento em ovinos da raça Morada Nova. Revista Brasileira de Zootecnia, v.26, n.2, p.265-271, 1997.

MACHADO, R.; SIMPLÍCIO, A.A. Efeito da raça do padreador e da época de monta sobre a eficiência reprodutiva de ovelhas deslanadas acasaladas com reprodutores de raças especializadas de corte. Revista Brasileira de Zootecnia, v.27, n.1, p.54-59, 1998.

MACHADO, R.; SIMPLÍCIO, A.A.; BARBIERI, M.E. Acasalamento entre ovelhas deslanadas e reprodutores especializados para corte: desempenho produtivo até a desmama. Revista Brasileira de Zootecnia, v.28, n.4, p.706712, 1999.

MANDIKI, S.N.M.; DERYCKE, G.; BISTER J.L., et al. Influence of season and age on sexual maturation parameters of Texel, Suffolk and Ile-de-France rams. 1. Testicular size, semen quality and reproductive capacity. Small Ruminant Research, v.28, n.1, p. 67-79, 1998.

MARTIN, G.B.; TJONDRONEGORO, S.; BLACKBERRY, M.A. Effects of nutrition on testicular size and the concentrations of gonadotrophins, testosterone and inhibin in plasma of mature male sheep. Journal of Reproduction and Fertility, v.101, p.121-128, 1994.

MATOS, C.A.P.; THOMAS, D.L.; NASH, T.G. et al. Genetic 
analyses of scrotal circumference size and growth in Rambouillet lambs. Journal of Animal Science, v.70, n.1, p.43-50, 1992.

McMANUS, C.; MIRANDA, R.M. Comparação das raças de ovinos Santa Inês e Bergamácia no Distrito Federal. Revista Brasileira de Zootecnia, v.26, n.5, p.1055-1059, 1997.

MICKELSEN, W.D.; PAISLEY, L.G.; DAHMEN, J.J. Seasonal variations in scrotal circumference, sperm quality and sexual ability in rams. JAVMA, v.181, n.4, p.376-380, 1982.

MIRANDA, R.M.; McMANUS, C. Desempenho de ovinos Bergamácia na região de Brasília. Revista Brasileira de Zootecnia, v.29, n.6, p.1661-1666, 2000.

MORAES, J.C.F. Avaliação reprodutiva do carneiro. Revista Brasileira de Reprodução Animal, v.21, n.1, p.10-19, 1997.

MORAES, J.C.F.; OLIVEIRA, N.M. Componentes da variância de medidas do perímetro escrotal e sua relevância na seleção de carneiros. Revista Brasileira de Reprodução Animal. n.3, p.257-264, 1991. (Suplemento)

MORAES, J.C.F.; OLIVEIRA, N.R.M. Componentes da avaliação andrológica e seu emprego na seleção de carneiros Romney Marsh. Revista Brasileira de Reprodução Animal, v.20, n.1, p.23-29, 1996.

QUESADA, M.C. Efeitos genéticos e ambientais sobre a produção e reprodução de ovinos deslanados no Distrito Federal. Brasília: Universidade de Brasília, 2000. 65p. Dissertação (Mestrado em Agronomia) - Universidade de Brasília, 2000.

REGE, J.E.O.; TOE, F.; MUKASA-MUGERWA, E. et al. Reproductive characteristics of Ethiopian highland sheep. II. Genetic parameters of semen characteristics and their relationships with testicular measurements in ram lambs. Small Ruminant Research, v.37, p.173-187, 2000.

SALGUEIRO, C.C.M.; NUNES, J.F. Estudo de características testiculares e espermáticas de caprinos e ovinos. Revista Brasileira de Reprodução Animal, v.23, n.3, p.231-232, 1999.

STATISTICAL ANALYSIS SYSTEM - SAS. User's guide. Version 8, Cary: 1999. 956p.

SECRETARIA DE AGRICULTURA DO DISTRITO FEDERAL - SADF. Plano de desenvolvimento Rural da Região Integrada de Desenvolvimento do Distrito Federal e entorno - RIDE - Programa de Ovinocultura. Brasília: 1999. $11 \mathrm{p}$.
SELAIVE-VILLARROEL, A.B.; MIES FILHO, A.; JOBIM, M.I.M. Estudo sobre produção de sêmen em carneiros. 1) Efeito da época do ano. Revista Brasileira de Reprodução Animal, v.9, n.4, p.161-169, 1985a.

SELAIVE-VILLARROEL, A.B.; MIES FILHO, A.; JOBIM, M.I.M. Estudo sobre produção de sêmen em carneiros. 2) Efeito da suplementação alimentar pré-acasalamento. Revista Brasileira de Reprodução Animal, v.9, n.4, p.181-190, 1985b.

SELAIVE-VILLARROEL, A.B.; MORAES, J.C.F. Estudos sobre produção de sêmen em carneiros. 3) Efeito da raça e da idade. Revista Brasileira de Reprodução Animal, v.11, n.1, p.37-45, 1987.

SIMPLÍCIO, A.A.; MACHADO, R.; ALVES, J.U. Manejo reprodutivo de caprinos em regiões tropicais. Piracicaba: Fundação de Estudos Agrários "Luiz de Queiroz", 1990. p.33-55.

SIMPLÍCIO, A.A.; RIERA, G.S., NELSON, E.A. et al. Seasonal variation in seminal and testicular characteristics of Brazilian Somali rams in the hot semi-arid climate of tropical northeast Brazil. Journal of Reproduction and Fertility, v.66, p.735-738, 1982.

UNANIAN, M.M.; FELICIANO SILVA, A.E.D.; McMANUS, C. et al. Características biométricas testiculares para avaliação de touros zebuínos da raça Nelore. Revista Brasileira de Zootecnia, v.29, n.1, p.136-144, 2000.

VILAR-FILHO, A.C.; BARNABE, V.H.; BIRGEL, E.H. Características testiculares e seminais de caprinos criados na região semi-árida do estado da Paraíba. I. Características testiculares. Revista Brasileira de Reprodução Animal, v.17, n.1-2, p.17-22, 1993.
Recebido em: 13/08/02 Aceito em: 10/03/03 